\title{
Angiotensina-(1-9) disminuye el daño renal en la hipertensión arterial renina independiente
}

\author{
Ulises Novoa', Sonia Abarca², Jackeline Moya², Jorge Jalii, María Paz Ocaranza-3. \\ 1 Departamento de Ciencias Básicas Biomédicas, Facultad de Ciencias de la Salud. Universidad de Talca. \\ 2 Laboratorio de Cardiología Molecular, División de Enfermedades Cardiovasculares \\ 3 Advanced Center for Chronic Disease (ACCDiS), Facultad de Medicina. Pontificia Universidad Católica de Chile.
}

Antecedentes: Angiotensina [Ang-(1-9)] disminuye la presión arterial (PA) y el remodelamiento cardíaco en la hipertensión arterial experimental independiente de renina. No hay antecedentes sobre el efecto de Ang-(1-9) en la progresión de daño renal de ratas hipertensas por expansión de volumen (con renina baja).

Objetivo: Determinar la participación de Ang-(19) en la progresión del daño renal en ratas hipertensas (DOCA-sal).

Métodos: Se utilizaron ratas Sprague Dawley macho de $150 \pm 10 \mathrm{~g}$ uninefrectomizadas tratadas con DOCA $(60 \mathrm{mg} / \mathrm{Kg} / 2$ veces sem, im) por 4 semanas. Como controles (Sham) se usaron ratas uninefrectomizadas. Desde la 2a semana las ratas DOCA, con presión arterial sistólica (PAS) $>140 \mathrm{mmHg}$, recibieron vehículo o Ang-(1-9) [602 ng/Kg min] por 2 semanas (minibomba Alzet). Se evaluó la respuesta inflamatoria y el daño renal profibrótico por la presencia de macrófagos infiltrativos y de miofibroblastos intersticiales. Se determinó, además, la presión arterial sistólica (PAS), masa corporal (MC), masa del riñón derecho (MR) y masa renal relativa (MRR).

Resultados: Se observó una disminución del daño renal en las ratas DOCA-sal, cuando recibieron Ang(1-9), respecto a aquellas que no la recibieron, evidenciado por una significativa disminución de macrófagos infiltrativos y miofibroblastos en el intersticio renal. El bloqueo de los receptores Mas y AT2, no tuvieron efectos adicionales.

Conclusión: En este modelo experimental, Ang(1-9) disminuyó la hipertensión y redujo significativamente la infiltración de macrófagos y la aparición de miofibroblastos en el intersticio renal. Estos resultados son la primera evidencia de que Ang-(1-9) reduce la fibrosis túbulo-intersticial renal y el daño renal hipertensivo. 


\section{Angiotensin (1-9) decreases renal damage in hypertension with low renin}

Angiotensin [Ang] - (1-9) decreases blood pressure (BP) and cardiac remodeling in renin independent hypertension. There are not studies about the effect of Ang- (1-9) in the progression of hypertensive renal damage by volume overload (low-renin). The aim of this study was to determine the effect of Ang- (1-9) on renal damage in volume overload hypertensive rats by (DOCA-salt rats).

Methods: Male Sprague Dawley rats, $150 \pm 10$ $\mathrm{g}$, were uni-nephrectomized and treated with DOCA $(60 \mathrm{mg} / \mathrm{Kg}) 2$ times per week, for 4 weeks. Uninephrectomized rats were used as controls (Sham). From the 2nd week on DOCA rats with systolic blood pressure (SBP)> $140 \mathrm{mmHg}$ received vehicle or Ang- (1-9) [602 $\mathrm{ng} / \mathrm{kg} \mathrm{min]}$ for 2 weeks (Alzet minipump). Inflammatory and profibrotic renal damage was evaluated by the presence of infiltrating macrophages and interstitial myofibroblasts.

Results: Compared to rats receiving vehicle renal damage in DOCA-salt rats decreased when they received Ang- (1-9), as evidenced by a significant decrease in infiltrating macrophages and myofibroblasts in the renal interstitium. Mas and AT2 receptor blockade had no additional effect. The SBP, body mass (BM), mass of the right kidney (MR) and relative renal mass (MRR) were also determined.

Conclusion: in this experimental model, Ang-(1-9) decreased hypertension and significantly reduced macrophage infiltration and the appearance of myofibroblasts in the renal interstitium. These results are the first evidence that Ang-(1-9) reduces renal tubulointerstitial fibrosis and hypertensive renal damage. 


\section{Introducción}

La hipertensión arterial (HTA), es una enfermedad multisistémica con una prevalencia en Chile de aproximadamente $26,9 \%{ }^{1}$.

El compromiso renal es uno de los principales responsables de la alta morbilidad y mortalidad atribuible a la HTA. El daño hipertensivo inicial, genera eventos inflamatorios (entre ellos la infiltración de macrófagos y linfocitos) que progresa con el tiempo hasta fibrosis túbulo intersticial, por depósito de matriz extracelular (MEC). En el depósito de la MEC, participan activamente los miofibroblastos (fenotipo activado de los fibroblastos), lo que finalmente lleva a la cicatrización y al deterioro funcional del riñón no tratado. ${ }^{2}$

La sobreestimulación del sistema renina-angiotensina (SRA) local y su principal componente, la angiotensina (Ang) II, juegan un papel clave en la progresión de las enfermedades renales. Ang II, no sólo ejerce efectos hemodinámicos, sino que actúa como un factor de crecimiento que refuerza la proliferación de miofibroblastos y células mesangiales. Además, tiene potentes efectos proinflamatorios por acción directa sobre los macrófagos y células $\mathrm{T}$. Ang II es producida a partir de Ang I por la enzima convertidora de angiotensina (ECA) y ejerce sus efectos renales a través de su receptor AT1 (RAT1). Se sabe que Ang II tiene efectos antihipertróficos y antiproliferativos a través de otro receptor (RAT2), sin embargo, la acción renal de éste es principalmente neonatal, contándose con escasa información sobre su rol en el riñón adulto. ${ }^{3}$

El descubrimiento de la ECA homóloga (ECA2) ${ }^{4-5}$ estableció una nueva vía paralela del SRA. En esta vía la ECA2 compite con la ECA por la hidrólisis de Ang I para formar Ang-(1-9) ${ }^{6}$; además, a través de su receptor específico Mas. ${ }^{9}$, ECA2 transforma Ang II en Ang-(1-7) ${ }^{7-8}$, conocida por sus acciones opuestas a las de Ang II,

No existen antecedentes sobre el efecto biológico de Ang(1-9) en el riñón. La información disponible ha sido aportada por nuestro grupo y muestran que Ang-(1-9), previene la hipertrofia cardiomiocitaria in vivo e in vitro ${ }^{10} \mathrm{y}$ disminuye el remodelamiento cardiovascular hipertensivo, inducido por Ang II ${ }^{11-12}$. Esto, sumado a otros hallazgos similares ${ }^{13-14-15-16}$ y al hecho de que Ang-(1-9), es parte de un eje opuesto al SRA clásico, apoyan el concepto que este péptido podría tener un papel en el desarrollo de las enfermedades renales, en oposición a los efectos deletéreos inducidos por Ang II, ya sea por acción directa sobre receptores de tipo AT2, o bien por transformación a Ang-(1-7) y unión al receptor Mas. De acuerdo a esto, el objetivo de este estudio fue determinar el efecto de la ad- ministración de Ang-(1-9) en la progresión del daño renal en ratas hipertensas.

\section{Materiales y Métodos}

La presente investigación se realizó de acuerdo a la "Guía para el cuidado y uso de animales de laboratorio" publicado por el "National Health Institute" (NIH N N $^{\circ}$-23, 1985) y fue aprobada por la Comisión de Investigación de la Facultad de Medicina de la Pontificia Universidad Católica de Chile.

\section{Modelo experimental de hipertensión por sobrecar- ga de volumen}

Se utilizaron ratas Sprague Dawley macho de $150 \pm 10 \mathrm{~g}$., uni-nefrectomizadas tratadas con desoxicorticosterona (DOCA, 60mg/Kg, Steraloids. Inc., USA, 2 veces sem, im) por 4 semanas. Como controles (Sham) se usaron ratas uni-nefrectomizadas. A partir de la 2a semana las ratas DOCA con HTA $>140 \mathrm{mmHg}$ fueron randomizadas a recibir Ang-(1-9) (602 ng/Kg min, vía yugular), Ang-(1-9) (602 ng/Kg min) + A779 (antagonista del receptor Mas de Ang-(1-7), 100 ng/Kg min, vía yugular) o Ang-(1-9) (602 $\mathrm{ng} / \mathrm{Kg} \mathrm{min}$ ) +PD123319 (antagonista del receptor tipo 2 de Ang II, 28,4 ng/kg min) durante 14 días. Al finalizar el tratamiento se determinó la presión arterial sistólica (PAS), diastólica (PAD) y masa corporal (MC). Una vez finalizadas las dos semanas de tratamiento, los animales fueron sacrificados, bajo anestesia con ketamina (35 mg/ $\mathrm{kg}$ de peso) y xilazina ( $7 \mathrm{mg} / \mathrm{kg}$ de peso).

\section{Obtención y preservación del tejido renal:}

Los riñones fueron extraídos inmediatamente post sacrificio, lavados cuidadosamente con suero fisiológico, fijados en Bouin por 12 horas y luego incluidos en bloques de parafina para histología y morfometría.

3. Parámetros hemodinámicos: La PAS fue medida semanalmente por pletismografía en la cola de las ratas previamente anestesiadas. ${ }^{17}$

\section{Evaluación de la Masa Renal Relativa (MRR):}

Se determinó mediante la relación entre la masa del rinón (MR) y el largo de la tibia (LT), de la forma $(\mathrm{MRR}=$ $\mathrm{MR} * 100 / \mathrm{LT})$.

\section{Evaluación de la inflamación renal:}

Se realizaron cortes transversales de $4 \mu \mathrm{m}$ de grosor de los tejidos renales fijados e incluidos en parafina. Posteriormente, cada uno de los cortes fueron desparafinados, 
hidratados y denaturados para exponer el antígeno con EDTA $1 \mathrm{mM}$ a pH $8 .{ }^{18} \mathrm{La}$ inmunomarcación se realizó con el Kit DAKO K0679. Los cortes se incubaron con el anticuerpo dirigido contra el marcador de macrófagos de rata ED1 (Serotec MCA341R) en una dilución 1/200 toda noche en una cámara húmeda a $4^{\circ} \mathrm{C}$. Posteriormente, los tejidos se lavaron y se incubaron con el anticuerpo secundario biotinilado durante $30 \mathrm{~min}$ a temperatura ambiente. Como método de detección se utilizó la técnica de Diaminobenzidina (Kit DAKO) y contra-tinción con hematoxilina. El número de células marcadas con ED-1 se midió de forma cuantitativa $^{19}$, evaluando la razón entre el número total de células positivas para ED1 y el área del tejido renal (células $\left.\operatorname{ED} 1(+) / \mathrm{mm}^{2}\right)$.

\section{Determinación de la activación de fibroblastos re- nales:}

Los cortes transversales de $4 \mu \mathrm{m}$ de grosor de riñón, fueron desparafinados y la inmunomarcación se realizó con el Kit DAKO K0679. Los cortes se incubaron con el anticuerpo dirigido contra alfa actina de músculo liso ( $\alpha$-SMA) (Sigma, St. Louis, Mo., USA.) en una dilución 1/1000 toda noche en una cámara húmeda a $4^{\circ} \mathrm{C}$. Posteriormente, los tejidos se lavaron y se incubaron con el anticuerpo secundario biotinilado durante $30 \mathrm{~min}$ a temperatura ambiente. Como método de detección se utilizó la técnica de Diaminobenzidina (Kit DAKO) y contra tinción con hematoxilina. La cuantificación morfométrica del área intersticial marcada por $\alpha$-SMA, se realizó, analizando toda el área córtico-medular del corte y descontando el área muscular lisa (también marcada por el anticuerpo). Los resultados se expresaron como el porcentaje del área total del campo estudiado con inmunotinción intersticial positiva.

8. Análisis de resultados: Los datos obtenidos se expresaron como promedio \pm error estándar de la media (SEM). Cada grupo experimental estuvo constituido por 7-8 animales. Para las comparaciones entre los grupos se usó análisis estadístico con ANOVA de un factor seguido por prueba de t-Student-Newman-Keuls. Se utilizó el programa estadístico SPSS (IBM Statistics) y se consideraron diferencias significativas con $\mathrm{p}<0,05$.

\section{Resultados}

\section{Efecto de Ang-1-9 sobre la PA y masa corporal (MC).} En las ratas del grupo control uni-nefrectomizado se obtuvo un promedio de PAS de $125 \pm 2 \mathrm{mmHg}$. Las ratas DOCA mostraron un aumento significativo de la PAS $(207 \pm 7$ vs $125 \pm 2$, ) y PAD (169 \pm 8 vs $106 \pm 2$, Tabla 1$)$ respecto al gru-
Tabla 1. Parámetros de presión arterial, masa corporal y masa renal de los distintos grupos experimentales. PAS = presión arterial sistólica ; PAD = presión arterial diastólica ; MC = masa corporal ; MR = masa renal ; MRR = masa renal relativa (mg Riñón/Largo de Tibia*100). Valores expresados en Promedio (SEM). * $p<0.05$ vs Sham, \#p<0.05 vs Doca, \& $p<0.05$ vs Doca/A(1-9) y Doca/A(1-9)/A779 (post-ANOVA).

\begin{tabular}{|l|r|r|r|r|r|}
\hline & S & D & D/A(1-9) & D/A(1-9)/A779 & D/A(1-9)/PD \\
\hline N & 12 & 19 & 14 & 7 & 6 \\
\hline PAS $(\mathrm{mmHg})$ & $125(2)$ & $207(7)^{*}$ & $161(6) \#$ & $155(6) \#$ & $180(10)^{\star} \&$ \\
\hline PAD $(\mathrm{mmHg})$ & $106(2)$ & $169(8)^{*}$ & $126(4) \#$ & $119(3) \#$ & $143(10)^{\star} \&$ \\
\hline MC $(\mathrm{g})$ & $306(9)$ & $244(11)^{*}$ & $217(11)^{*}$ & $245(15)^{*}$ & $229(4)^{\star}$ \\
\hline MR $(\mathrm{g})$ & $1.68(0.07)$ & $2.21(0.14)$ & $2.15(0.18)$ & $2.45(0.21)$ & $1.94(0.12)$ \\
\hline MRR & $42.9(1.7)$ & $59.0(3.6)$ & $56.7(4.5)$ & $67.4(6.7)$ & $55.6(3.9)$ \\
\hline
\end{tabular}

po control sham, respectivamente. Las ratas hipertensas DOCA que recibieron Ang-(1-9) mostraron una disminución significativa de la PAS y PAD vs las ratas DOCA

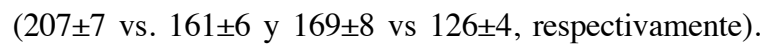
Las ratas hipertensas que recibieron la coadministración de Ang-(1-9) y A779 igualmente disminuyeron la PAS y PAD respecto a las ratas DOCA (207 \pm 7 vs. $155 \pm 6$ y $169 \pm 8$ vs $119 \pm 3$, respectivamente). No se observaron diferencias en la PAS y PAD entre las ratas DOCA+Ang-(1-9) y DOCA+Ang-(1-9)+A779. La coadministración de PD123319 modificó significativamente el efecto antihipertensivo de Ang-(1-9), aumentado la PAS y PAD (161 \pm 6 vs $180 \pm 10$ y $126 \pm 4$ vs $143 \pm 10$ ). Sin embargo, no alcanzó las cifras tensionales de las ratas DOCA que recibieron solo vehículo. La masa corporal (MC) disminuyó significativamente en las ratas DOCA respecto a las ratas controles. La coinfusión de Ang-(1-9), A779 y PD123319 no modificó la disminución de la MC. La masa renal (MR) se mantuvo sin variación entre los grupos experimentales. La MRR también se mantuvo sin variación, excepto para el grupo DOCA-Ang-(1-9) tratado con A779, donde la MRR fue significativamente mayor respecto al SHAM (67.4 $\pm 6.7 \mathrm{vs}$ $42.9 \pm 1.7)$, (Tabla 1$)$.

\section{Evaluación cuantitativa de la infiltración de macró- fagos.}

Los macrófagos presentes, tanto en el intersticio renal como en los glomérulos, se determinaron por la expresión del antígeno específico ED1 (Figura 1). En el grupo SHAM, los macrófagos infiltrativos renales se detectaron en moderado número (Figura 1A y 2). Sin embargo, en el grupo DOCA, la cantidad de macrófagos infiltrativos aumentó significativamente respecto al grupo SHAM, (Figura 1B y 2). En las ratas DOCA tratadas con Ang-(1-9), la 
Figura 1. Ang-(1-9) disminuye la infiltración de macrófagos al intersticio renal. En condiciones normales, los macrófagos están ausentes o en escaso número en el intersticio renal (figura 1A), sin embargo, en el modelo DOCA, los macrófagos invaden el intersticio en gran número (figura 1B). El tratamiento con Ang-(1-9) redujo la cantidad de macrófagos intersticiales infiltrativos en este modelo (figura 1C). Cuando se bloquea simultáneamente el receptor MAS (fig. 1D) o RAT2 (fig. 1E), no se observan efectos sobre la reducción de macrófagos infiltrativos inducida por Ang-(1-9). Las flechas indican la presencia de macrófagos. La barra representa una longitud de $25 \mu \mathrm{m}$.

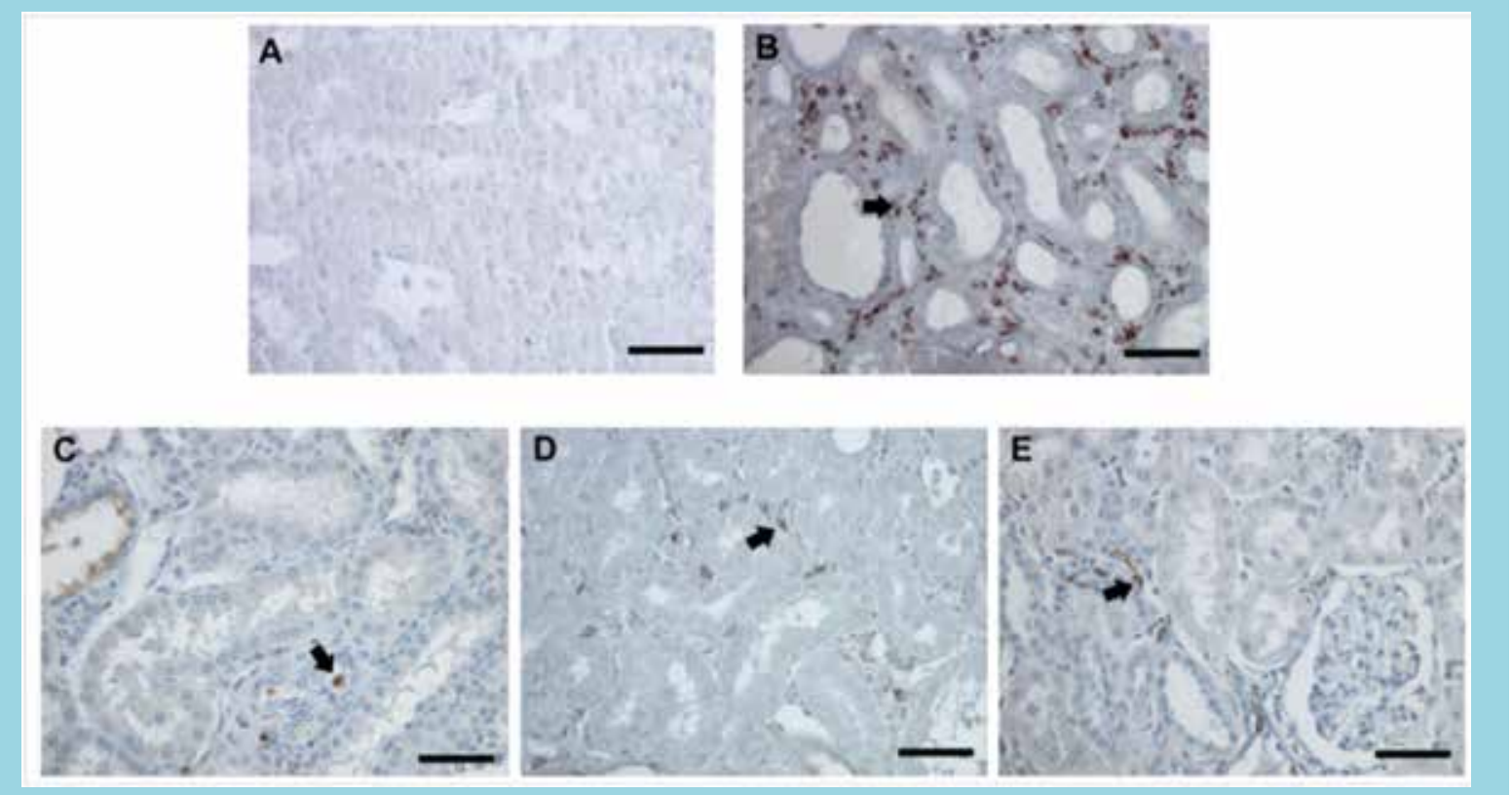

Figura 2. Cuantificación de células ED1 positivas (macrófagos infiltrativos) en el intersticio renal. Los macrófagos intersticiales infiltrativos, aumentan significativamente en los riñones de las ratas con hipertensión inducida por DOCA comparados con el control SHAM. La infusión de Ang-(1-9) redujo significativamente la cantidad de macrófagos en este modelo. El bloqueo simultáneo de MAS (con A779) o RAT2 (con PD123319), no tuvo efectos significativos en la reducción inducida por Ang-(1-9). Se analizó la cantidad de células ED1(+) por área de superficie ( $\mathrm{mm} 2)$ analizada. Símbolos: * $p<0.05$ vs Sham; \# $=p<0.05$ vs DOCA (post-ANOVA).

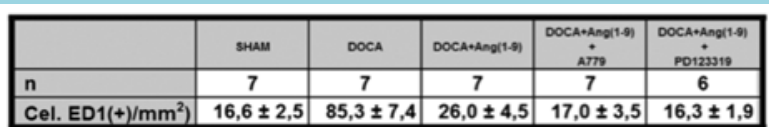

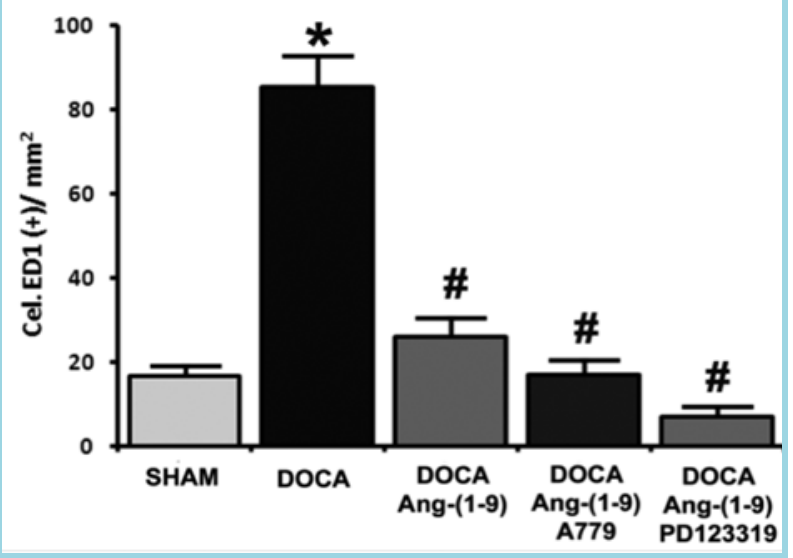

cantidad de macrófagos infiltrativos disminuyó significativamente respecto a aquellas que no recibieron tratamiento (Figura 1C y 2) De igual forma, se observó que esta tendencia no cambiaba en las ratas DOCA-Ang-(1-9) cuando se bloqueaban simultáneamente los receptores MAS y RAT2 (Figura 1 y 2). La cantidad de macrófagos infiltrativos observada en los grupos tratados con Ang-(1-9) no fue significativamente diferente a la del grupo control SHAM (figura 2).

\section{Evaluación de la activación de fibroblastos.}

Los fibroblastos activados o miofibroblastos expresan algunas biomoléculas propias de su fenotipo, como la actina de músculo liso, tipo $\alpha$ ( $\alpha$-SMA). En riñones de las ratas Sham, la expresión de miofibroblastos (células $\alpha$-SMA positivas), está confinada a células de músculo liso vascular, con una pequeña cantidad presente en el intersticio renal (Figura 3A). Sin embargo, en el modelo DOCA-sal el intersticio renal es invadido por miofibroblastos, que también expresan $\alpha$-SMA, de tal forma que la cantidad de miofibroblastos intersticiales fue significativamente superior al grupo SHAM (Figuras 3B y 4). Ang-(1-9); disminuyó significativamente la cantidad de miofibroblastos intersticiales en las ratas DOCA que recibieron solo vehículo (figura 3C y 4). El bloqueo de los receptores Mas y RAT2, 
Figura 3. Ang-(1-9) disminuye la activación de fibroblastos en el intersticio renal. En condiciones normales, œSMA se expresa sólo en el músculo liso vascular (figura $3 \mathrm{~A}$, flecha delineada), sin embargo, en el modelo DOCA, se puede ver que el intersticio renal es invadido por una gran cantidad de miofibroblastos que también expresan este marcador (figura 3B, flecha sólida). El tratamiento con Ang-(1-9) redujo la cantidad de miofibroblastos intersticiales en este modelo (figura 3C). El bloqueo simultáneo de MAS (figura 3D) o RAT2 (figura 3E), no tuvo efectos sobre esta reducción. La barra indica una longitud de $100 \mu \mathrm{m}$.

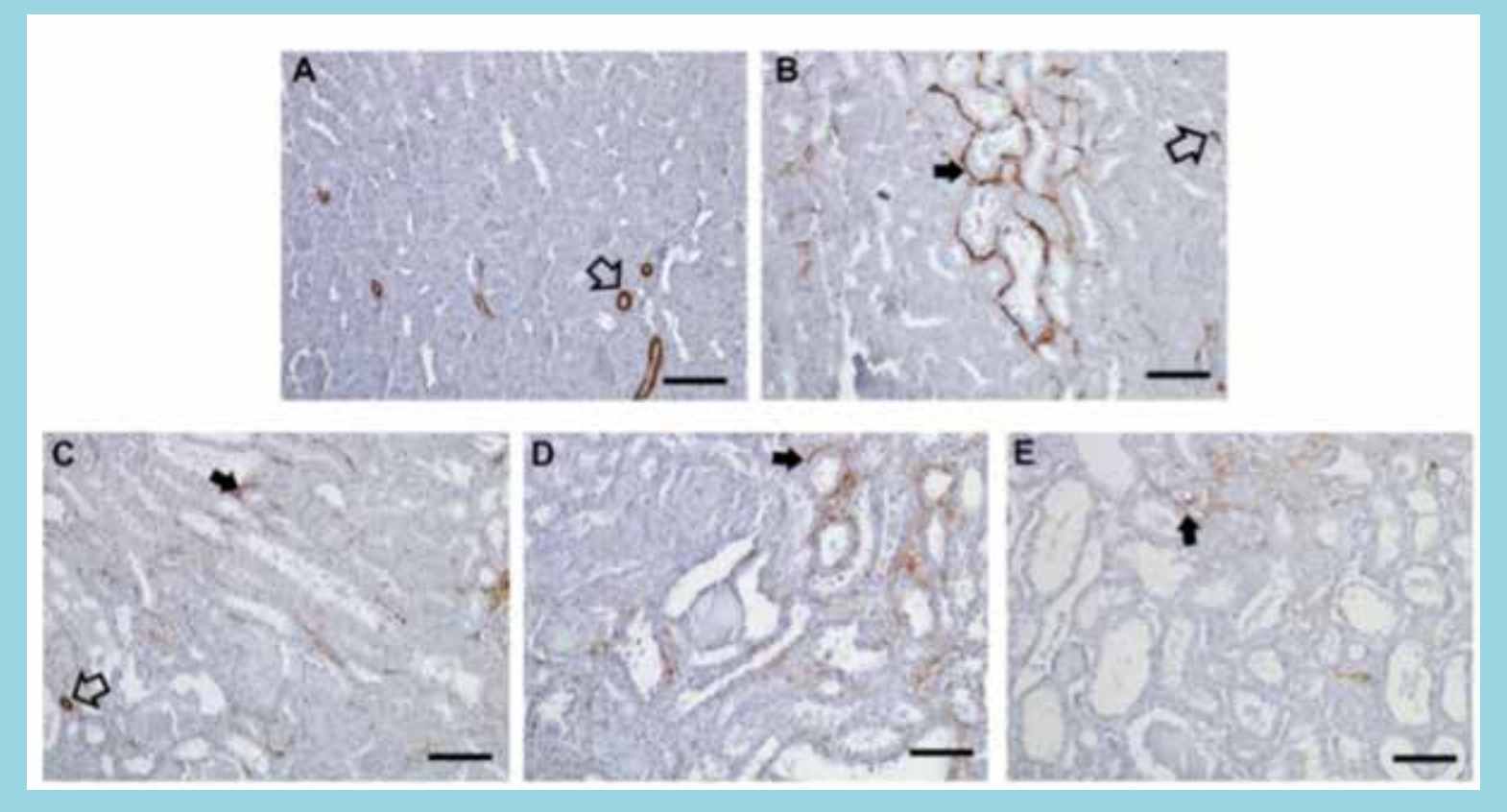

Figura 4. Cuantificación de œSMA intersticial (miofibroblastos) en los grupos experimentales. Los miofibroblastos intersticiales, aumentan significativamente en los riñones de las ratas con hipertensión inducida por DOCA, respecto al control SHAM. La infusión de Ang-(1-9) redujo significativamente la cantidad de miofibroblastos en este modelo. El bloqueo simultáneo de MAS (con A779) o RAT2 (con PD123319), no tuvo efectos significativos en la reducción inducida por Ang-(1-9). Además se observa que el bloqueo de RAT2 redujo la cantidad de miofibroblastos a niveles similares al control. Se analiza la cantidad de miofibroblastos como porcentaje de células œSMA(+) en el total de la superficie analizada. Símbolos: ${ }^{*}=p<0.05$ vs Sham; $\#=p<0.05$ vs DOCA (post-ANOVA).

\begin{tabular}{|c|c|c|c|c|c|}
\hline & strem & DocA & Dochathortist & 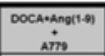 & 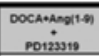 \\
\hline $\mathrm{n}$ & 6 & 7 & 8 & 8 & 6 \\
\hline aSMA(\%) x100 & $0,8 \pm 0,1$ & $15,3 \pm$ & $6,1 \pm 1,1$ & $6,9 \pm 2,3$ & $1,7 \pm 0,2$ \\
\hline
\end{tabular}

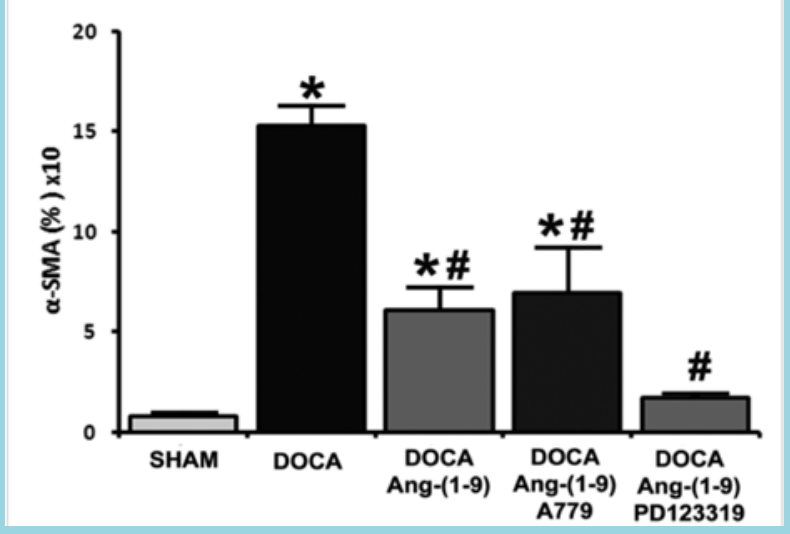

no modificó el efecto de Ang-(1-9) [Figura 4]. Sólo en el grupo DOCA-Ang-(1-9) tratado con el antagonista RAT2 (PD123319) se obtuvo una disminución a niveles similares al grupo SHAM (Figura 4).

\section{Discusión}

Nuestros resultados muestran que: 1.- El aumento significativo de la infiltración de macrófagos al intersticio renal, producida en este modelo pro-hipertensivo (DOCA-sal), disminuyó post administración de Ang-(1-9). 2.- La aparición de miofibroblastos en el intersticio renal, producto del daño inducido por la HTA, puede ser disminuida por la administración de Ang-(1-9). 3.- Los efectos protectores ejercidos por la administración de Ang-(1-9), no son modificados al bloquear el receptor Mas y AT2.

En este estudio, evaluamos dos elementos claves en el establecimiento de la fibrosis túbulo-intersticial, la infiltración de macrófagos al parénquima renal y la presencia de fibroblastos activados en el intersticio renal ${ }^{20}$. La importancia de evaluar estos marcadores tempranos de daño renal, radica en que se ha establecido que el deterioro a largo plazo y en definitiva el destino del riñón enfermo, puede predecirse por el daño túbulo-intersticial observado en las etapas iniciales de la enfermedad ${ }^{21}$. Tanto la infiltración de macrófagos como la activación de fibroblastos son 
procesos regulados, al menos en parte, por Ang II. ${ }^{22}$ Nuestros resultados muestran que la administración intravenosa de Ang-(1-9) puede disminuir la infiltración de macrófagos al parénquima renal, reteniendo un fenotipo similar al control no hipertenso. Estos resultados, adquieren especial importancia, por cuanto son la primera evidencia de un efecto biológico de Ang-(1-9) sobre la fibrosis túbulo-intersticial renal hipertensiva.

Actualmente se sabe que el daño renal hipertensivo progresa a través de un conjunto de eventos fisiopatológicos comunes ${ }^{20}$. La injuria inicial genera un proceso inflamatorio de carácter infiltrativo-proliferativo que involucra células residentes y extra-renales, entre los cuales se encuentran los macrófagos ${ }^{23-24}$. Si el riñón enfermo no es tratado a tiempo, estos elementos iniciales, desencadenan una compleja serie de interacciones celulares y moleculares que terminarán en una insuficiencia renal crónica (IRC) aun cuando el proceso que desencadenó el daño ya no esté presente ${ }^{20}$.

Lo que provoca la progresiva pérdida de la función renal, es la cicatrización del parénquima renal, principalmente por depósito de la matriz extracelular (MEC). En este evento, participan activamente los miofibroblastos, en cuya aparición intersticial tiene principal importancia la Ang II, que proviene de la sobreestimulación del SRA por eventos proinflamatorios anteriores ${ }^{25}$. Los miofibroblastos se distinguen de los fibroblastos no activados por la expresión de marcadores propios como lo es $\alpha$ SMA.

En el presente trabajo, mostramos que la administración de Ang-(1-9) disminuyó significativamente la aparición intersticial de miofibroblastos inducida por DOCA-sal. Este resultado, es relevante, por cuanto son los miofibroblastos uno de los responsables directos de la destrucción funcional del tejido renal que se observa en la insuficiencia renal crónica ${ }^{2}$.

Estos resultados nos ayudan a comprender mejor el complejo papel que cumple el SRA durante el desarrollo de las enfermedades renales, en especial sobre sus mecanismos contrarregulatorios fisiológicos y fisiopatológicos, que limitan sus efectos nocivos sobre el tejido renal ${ }^{26}$.

La vía paralela del SRA ${ }^{4-5}$, específicamente la ECA-2 y la Ang-(1-7) han emergido como novedosos blancos terapéuticos para el tratamiento de la HTA y de sus complicaciones cardiovasculares. La ECA-2 no sólo participa en la metabolización de Ang I y Ang II y produce Ang-(1-9) y Ang (1-7) respectivamente, sino que también hidroliza otros péptidos vasoactivos como apelina-13,
des-Arg ${ }^{9}$-bradikinina, neurotensina, y péptidos opiodes ${ }^{5}$. Estos productos presentan una variedad de funciones por lo que la ECA-2 puede tener un rol en inflamación, neurotransmisión y funciones cardiovasculares. Aunque la ECA-2 hidroliza varios sustratos, la producción de Ang-(1 -7) parece tener uno de los roles más importante a nivel cardiovascular ${ }^{27}$. Hay evidencia que Ang-(1-7) contrarresta algunos efectos cardiovasculares y renales de Ang II, a través de su receptor Mas. Ang-(1-9) es sustrato para la obtención de Ang-(1-7) por la ECA, por lo tanto, nosotros investigamos la posibilidad de que los efectos que observamos con la administración de Ang-(1-9) se debieran a esta conversión. Nuestros resultados demostraron, que el bloqueo de Mas con su antagonista específico A779, no modificó la reducción de macrófagos y miofibroblastos inducida por Ang-(1-9) en el modelo DOCA-sal, indicando que Ang-(1-7) no es la causante de este efecto.

En cuanto al mecanismo por el cual Ang-(1-9) produce su efecto benéfico a nivel renal una posibilidad es que el RAT2 pudiera participar en el mecanismo de acción de Ang-(1-9). Se sabe que la señalización a través de este receptor, desencadena efectos antagónicos a los ejercidos por Ang $\mathrm{II}^{28}$. Algunas investigaciones recientes, sugieren que al menos parte de los efectos de Ang-(1-9) a nivel cardiovascular pueden ser mediados por el RAT2 $29-30-31$. A nivel renal, RAT2 parece ejercer efectos sobre los vasos de resistencia preglomerulares neonatales31. En el riñón adulto, su función todavía es objeto de investigación, aunque hay evidencia reciente de su participación a nivel de recaptación de sodio y proteínas en los túbulos renales ${ }^{29-31}$. Para evaluar la importancia de RAT2 en nuestro modelo experimental, bloqueamos el receptor AT2 con su antagonista PD123319. Los resultados muestran que a nivel renal los efectos benéficos de Ang-(1-9) no son mediados por el RAT2.

En conclusión, nuestros resultados entregan los primeros antecedentes del efecto biológico benéfico de Ang-(1-9) en la progresión del daño renal hipertensivo. La modulación de los niveles de Ang-(1-9) podría constituir un nuevo blanco farmacológico para el tratamiento y prevención del daño renal.

\section{Agradecimientos}

Este trabajo fue financiado por Comisión Nacional de Investigación Científica y Tecnológica (CONICYT), Chile: FONDEF D11I1122 a M.P.O y FONDAP 15130011 a M.P.O. 


\section{Referencias:}

1. KEARNEY PM, WHELTON M, REYNOLDS K, MUNTNER P, WHELTON PK, HE J. Global burden of hypertension: analysis of worldwide data. Lancet 2005; 365: 217-223.

2. HODGKINS K, SCHNAPER HW. Tubulointerstitial injury and progression of chronic kidney disease. Pediatr Nephrol 2012; 27: 901-909.

3. BAGBY SP, LEBARD LS, LUO Z, OGDEN BE, CORLESS C, MCPHERSON ED, et al. ANG II AT(1) and AT(2) receptors in developing kidney of normal microswine. Am J Physiol Renal Physiol 2002; 283: F755-F764.

4. TIPNIS S, HOOPER N, HYDE R, KARRAN E, CHRISTIE G, TURNER AJ, et al. A human homolog of angiotensin converting enzyme. Cloning and functional expression as a captopril-insensitive cardoxypeptidase. J. Biol. Chem 2000; 275: 33238-33243.

5. DONOGHUE M, HSIEH F, BARONAS E, GODBOUT $\mathrm{K}$, GOSSELIN M, STAGLIANO N, et al. A novel angiotensin-converting enzyme related carboxypeptidase (ACE2) converts angiotensin I to angiotensin 1-9. Circ. Res 2000; 87: E1-E9.

6. VICKERS CH, HALES P, KAUSHIK H, DICK L, GAVIN J, TANG J, et al. Hydrolisis of biological peptides by human angiotensin-converting enzyme-related carboxypeptidase (ACE2). J. Biol. Chem 2002; 277: 14838-14843.

7. RICE G, THOMAS D, GRANT P, TURNER A, HOOPER N. Evaluation of angiotensin-converting enzyme (ACE), its homologue ACE2 and neprilysin in angiotensin peptide metabolism. Biochem J 2004; 383:45-51

8. SANTOS R, SIMOES E, SILVA A, MARIC C, SILVA D, DE BUHR I, et al. Angiotensin-(1-7) is an endogenous ligand for the G protein-coupled receptor MAS. Proc Natl Acad Sci 2003; 100:8258-8263.

9. SANTOS R CASTRO C, GAVA E, PINHEIRO S, ALMEIDA A, PAULA RD, et al. Impairment of in vitro and in vivo heart function in angiotensin-(1-7) receptor MAS knockout mice. Hypertension 2006; 47: 996-1002.

10. OCARANZA M, LAVANDERO S, JALIL J, MOYA J, PINTO M, NOVOA U, et al. Angiotensin-(1-9) regulates cardiac hypertrophy in vivo and in vitro. Journal of Hypertension 2010; 28:1054-1064.

11. LAGOS T, ESCUDE N, NOVOA U, GODOY I, CHIONG M, et al. Angitensina 1-9 previene la hipertensión arterial y el remo-delamiento de la pared aortica inducido por Angiotensina II. Rev Chil Cardiol, Libro resúmenes 2009; 38:333-334.

12. GONZÁLEZ L, CONTRERAS A, NOVOA U, GODOY I, CHIONG M, et al. Evidencias in vitro e in vivo de la acción antihipertrófica de Angitensina 1-9 en el cardiomiocito. Rev Chil Cardiol, Libro resúmenes 2009; 38:299-300.

13. FERRARIO C. Angiotensin-converting enzyme 2 and angioten-sin-(1-7): an evolving story in cardiovascular regulation. Hypertension 2006; 47: 515-521.

14. OCARANZA M, MOYA J, PINTO M, ESCUDEROS N, VALENZUELA F, VARAS M, et al. Menores niveles tisulares de la enzima convertidora de angiotensina I homóloga (ECA-2) y angiotensina-(1-9) están asociados a mayor remodelamiento de la pared aórtica de las ratas hipertensas. Rev Chil Cardiol 2010; 29:69-82.

15. OCARANZA M, PIDDO A, FAÚNDEZ P LAVANDERO S, JALIL, J. Angiotensin I-converting enzyme gene polymorphism influences chronic hypertensive response in the rat Goldblatt model. J. Hypertension 2002; 20:413-420.

16. OLIVERI C, OCARANZA M, CAMPOS X, LAVANDERO S, JALIL J. Angiotensin I-converting enzyme modulates neutral en-dopeptidase activity in the rat. Hypertension 2001; 38:650654.

17. OCARANZA M, GODOY I, JALIL J, VARAS M, COLLANTES P, PINTO M, et al. Enalapril attenuates down-regulation of angiotensin-converting enzyme 2 in the late phase of ventricular dysfunction in myocardial infracted rat. Hypertension 2006; 48:572-578

17. OCARANZA M, GODOY I, JALIL J, VARAS M, PATRICIA COLLANTES P PINTO M, et al. Enalapril attenuates down-regulation of angiotensin-converting enzyme 2 in the late phase of ventricular dysfunction in myocardial infracted rat. Hypertension 2006; 48:572-578

18. SALVADÓ M, MARTÍNEZ S, ÁLVARO T, BARBERA M, 
RISA R, et al. Técnicas de desenmascaramiento antigénico en inmunohistoquímica. Rev Esp Patol 2001; 34:255260.

19. LOMBARDI DM, VISWANATHAN M, VIO CP, SAAVEDRA JM, SCHWARTZ SM, JOHNSON RJ. Renal and vascular injury induced by exogenous angiotensin II is AT1 receptor-dependent. Nephron. 2001: 8766-74.

20. RONDÓN M, LÓPEZ P. La progresión de la enfermedad renal: Una revisión. Med-ULA 1999; 532-38

21. NATH KA. Tubulointerstitial changes as a major determinant in the progression of renal damage. Am J Kidney Dis 1992; 20: $1-17$.

22. GONZÁLEZ P. Variación genética y progresión de la insuficiencia renal. Nefrología 2003: 23: 36-41.

23. NICOLIC-PATERSON DJ, ATKINS R. The role of macrophages in glomerulonephritis. Nephrol. Dial. Transplant 2001; 16(5): 3-7.

24. ERWIG LP, KLUTH DC, REES AJ. Macrophage heterogeneity in renal inflammation. Nephrol Dial Transplant 2003; 18: 1962-1965.

25. MEZZANO A, AROS C. Enfermedad renal crónica: clasificación, mecanismos de progresión y estrategias de renoprotección. Rev. Méd. Chile 2005; 133(3): 338-348.
26. MEZZANO A, RUIZ-ORTEGA M, EGIDO J. Angiotensin II and renal fibrosis. Hypertension 2001; 38: 635-638.

27. ALLRED AJ, DIZ DI, FERRARIO CM, CHAPPELL MC. Pathways for angiotensin-(1 -7) metabolism in pulmonary and renal tissues. Am J Physiol Renal Physiol. 2000; 279: F841 $-850$

28. CLARKE C, FLORES-MUÑOZ M, MCKINNEY CA, MILLIGAN G, NICKLIN SA. Regulation of cardiovascular remodeling by the counter-regulatory axis of the renin-angiotensin system. Future Cardiol. 2013; 9(1):23-38

29. ALI Q, WU Y, HUSSAIN T. Chronic AT2 receptor activation increases renal ACE2 activity, attenuates AT1 receptor function and blood pressure in obese Zucker rats. Kidney Int 2013; 84(5):931-939

30. BADER M. ACE2, angiotensin-(1-7), and Mas: the other side of the coin. Bader M. Pflugers Arch 2013; 465(1):79-85.

31. SCHIE $\beta$ L IM, CASTROP H. Angiotensin II AT2 receptor activation attenuates AT1 receptor-induced increases in the glomerular filtration of albumin: a multiphoton microscopy study. Am J Physiol Renal Physiol 2013; 305(8):F1189-f1200.

32. RATLIFF B, RODEBAUGH J, SEKULIC M, DONG KW, SOLHAUG M. Nitric oxide synthase and renin-angiotensin gene expression and NOS function in the postnatal renal resistance vasculature. Pediatr Nephrol 2009; 24(2): 355-365. 
I. En el trabajo presentado durante el pasado Congreso de Cardiología 2014, llamado "Activación de componentes de la vía de señalización RhoA/Rho kinasa en leucocitos de pacientes con insuficiencia cardíaca bajo tratamiento", y publicado en las pags. 29 y 30 del Libro de Resúmenes, faltó constatar la siguiente información:

1) Autores e institución a la que pertenecen. Debe decir:

Jackeline Moya, Luigi Gabrielli, Paul Mac Nab, Pablo Castro, Samuel Córdova, Iván Godoy, Víctor Rossel1, Luis Farías, Lorena García2, Ivonne Padilla, María Paz Ocaranza, Jorge E Jalil.

P. Universidad Católica de Chile, Escuela de Medicina, División de Enfermedades Cardiovasculares, Laboratorio de Cardiología Molecular; Hospital del Salvador, Servicio de Medicina Interna, Unidad de Cardiología ${ }^{1}$; Universidad de Chile, Facultad de Ciencias Químicas y Farmacéuticas. ${ }^{2}$

2) Financiamiento: FONDECYT 1121060

II. En la Revista de Resúmenes relativa al Congreso 2014, fue publicado el trabajo "Cambios agudos en la función auricular derecha post uso de Iloprost inhalatorio en pacientes con hipertensión arterial pulmonar: estudio con técnicas de deformación de imagen", en que se omitió a uno de los autores. Debe decir:

Andrés Kanacri, Luigi Gabrielli, Julián Vega, Rodrigo Saavedra, Sebastián Herrera, Pablo Castro, Pablo Sepúlveda.

Hospital Clínico P. Universidad Católica de Chile. 